doi:10.1016/j.socscimed.2006.04.018

Copyright (c) 2006 Elsevier Ltd All rights reserved.

\title{
Health care costs in the last year of life-The Dutch experience
}

\author{
Johan J. Polder ${ }^{a,} *$, Jan J. Barendregt ${ }^{b}$ and Hans van Oers ${ }^{a}$ \\ ${ }^{a}$ RIVM, Bilthoven, The Netherlands \\ ${ }^{b}$ School of Population Health, University of Queensland, Australia
}

Available online 14 June 2006.

\begin{abstract}
Health expenditure depends heavily on age. Common wisdom is that the age pattern is dominated by costs in the last year of life. Knowledge about these costs is important for the debate on the future development of health expenditure. According to the 'red herring' argument traditional projection methods overestimate the influence of ageing because improvements in life expectancy will postpone rather than raise health expenditure. This paper has four objectives: (1) to estimate health care costs in the last year of life in the Netherlands; (2) to describe age patterns and differences between causes of death for men and women; (3) to compare cost profiles of decedents and survivors; and (4) to use these figures in projections of future health expenditure.
\end{abstract}

We used health insurance data of 2.1 million persons (13\% of the Dutch population), linked at the individual level with data on the use of home care and nursing homes and causes of death in 1999.

On average, health care costs amounted to 1100 Euro per person. Costs per decedent were 13.5 times higher and approximated 14,906 Euro in the last year of life. Most costs related to hospital care (54\%) and nursing home care (19\%). Among the major causes of death, costs were highest for cancer $(19,000$ Euro) and lowest for myocardial infarctions (8068 Euro). Between the other causes of death, however, cost differences were rather limited. On average costs for the younger decedents were higher than for people who died at higher ages.

Ten per cent of total health expenditure was associated with the health care use of people in their last year of life. Increasing longevity will result in higher costs because people live longer. The decline of costs in the last year of life with increasing age will have a moderate lowering effect. Our projection demonstrated a $10 \%$ decline in the growth rate of future health expenditure compared to conventional projection methods.

Keywords: Health expenditure; Ageing; Last year of life; Longevity; Causes of death; Cost projection; The Netherlands 
Social Science \& Medicine Volume 63, Issue 7 , October 2006, Pages 1720-1731

\section{Introduction}

Health care costs depend heavily on age (Lubitz, Greenberg, Gorina, Wartzman, \& Gibson, 2001; Meerding, Bonneux, Polder, Koopmanschap, \& van der Maas, 1998). Common wisdom is that the age pattern in health care costs is dominated by the costs made in the last year of life (Scitovsky, 1994; Zweifel, Felder, \& Meiers, 1999). Several studies have been performed focussing on different aspects of health expenditure in the last year of life. Most studies focus on specific groups as Medicare beneficiaries (Lubitz, Cai, Kramarow, \& Lentzner, 2003; Lubitz \& Riley, 1993; Lunney, Lynn, \& Hogan, 2002; Riley, Lubitz, Prihoda, \& Rabey, 1987), adults (Liu \& Yang, 2002), elderly (Lubitz et al., 2003) or institutionalised persons (O'Neill, Groom, Avery, Boot, \& Thornhill, 2000). Only a few studies reported costs by cause of death, showing highest costs for cancer and lowest for heart disease (Lubitz et al., 2003; Riley et al., 1987). The only study reporting on the Netherlands used a small, non-representative sample (Stooker et al., 2001).

Knowledge about costs in the last year of life is important for the debate on the future development of health expenditure. According to the 'red herring' argument traditional projection methods overestimate the influence of ageing because improvements in life expectancy will postpone rather than raise health expenditure (Zweifel et al., 1999; Zweifel, Felder, \& Werblow, 2004).

This paper has four objectives: (1) to estimate health care costs in the last year of life in the Netherlands; (2) to describe age patterns and differences between causes of death for men and women; (3) to compare costs profiles of decedents and survivors; and (4) to use these figures in more advanced projections of future health expenditure.

\section{Data and methods}

\section{Health services included}

The Dutch health care system provides comprehensive coverage for a wide range of services, but is also known for its complex governance structure (Exter, Hermans, Dosljak, \& Busse, 2004). The insurance system is divided into three compartments. The first compartment covers exceptional medical expenses associated with long-term care. The second compartment covers normal, necessary medical care: physicians, hospitals, drugs and related services (cure). The costs are largely covered by (social) sickness fund insurance $(64.1 \%$ of the population) and private medical insurance (35.9\% of the population). The third compartment covers the supplementary forms of care regarded as being less necessary, as for instance eyeglasses and dental care for adults and elderly. Outside these compartments substantial costs are paid by the government and other parties.

In our analysis of health care costs in the last year of life we included all services belonging to the second compartment as well as expenditure on nursing homes and home care from the first compartment. Total expenditure in the sample (see below) amounted $€ 3091$ million, corresponding with $€ 19,400$ million at national level (Table 1). Depending on the definition of health care our sample covered $62.4-77.4 \%$ of total health expenditure. The lowest share relates to the broad definition of the Dutch government that also includes residential facilities for elderly and people with intellectual disabilities (van Mosseveld \& Smit, 2005). According to the international standards of the OECD these services do not belong 
to the health care system (OECD, 2000). In definitions of the OECD System of Health Accounts (SHA) our sample covers $68.5 \%$ of total health expenditure (van Mosseveld \& Smit, 2005). If we focus on the social security and health insurance part of the SHA definition (including out-of-pocket payments), our sample comprised $77.4 \%$ of total expenditure.

Table 1.

Key characteristics of the study group compared to the Dutch population, 1999

\begin{tabular}{|c|c|c|}
\hline & Study group & Population \\
\hline Expenditure included services ( $€ 1 \mathrm{mln}$ ) & 3091 & 19,419 \\
\hline \multicolumn{3}{|l|}{ Share in total health expenditure (\%) } \\
\hline Definition Dutch government & & $62.4 \%$ \\
\hline Definition OECD System of Health Accounts (SHA) & & $68.5 \%$ \\
\hline OECD SHA, social security and health insurance ${ }^{a}$ & & $77.4 \%$ \\
\hline Population (number) & $2,118,012$ & $15,812,077$ \\
\hline share $(\%)$ & $13.4 \%$ & $100 \%$ \\
\hline Insurance scheme: social/private health insurance (\%) & $66.5 / 33.5$ & $64.1 / 35.9$ \\
\hline Gender: Male/female (\%) & $48.2 / 51.8$ & $49.5 / 50.5$ \\
\hline \multicolumn{3}{|l|}{ Age } \\
\hline $0-44$ & $57.2 \%$ & $62.3 \%$ \\
\hline $45-64$ & $25.5 \%$ & $24.2 \%$ \\
\hline $65-74$ & $9.1 \%$ & $7.5 \%$ \\
\hline $75-84$ & $6.1 \%$ & $4.6 \%$ \\
\hline $85+$ & $2.1 \%$ & $1.4 \%$ \\
\hline Mortality, number decedents ${ }^{b}$ & 24,265 & 140,487 \\
\hline mortality rate $(\%)$ & $1.15 \%$ & $0.89 \%$ \\
\hline mortality rate, corrected for age structure population (\%) & $0.89 \%$ & $0.89 \%$ \\
\hline male/female (\%) & $46.7 / 53.3$ & $49.0 / 51.0$ \\
\hline \multicolumn{3}{|l|}{ Age at death } \\
\hline $0-44$ & $3.3 \%$ & $5.0 \%$ \\
\hline $45-64$ & $12.4 \%$ & $14.6 \%$ \\
\hline $65-74$ & $19.7 \%$ & $19.8 \%$ \\
\hline $75-84$ & $33.7 \%$ & $32.1 \%$ \\
\hline $85+$ & $30.9 \%$ & $28.5 \%$ \\
\hline \multicolumn{3}{|l|}{ Causes of death ${ }^{b}$} \\
\hline Infectious diseases & $1.2 \%$ & $1.2 \%$ \\
\hline
\end{tabular}




\begin{tabular}{|l|l|l|}
\hline & Study group & Population \\
\hline Cancer & $29.8 \%$ & $27.9 \%$ \\
\hline Diabetes & $2.5 \%$ & $2.4 \%$ \\
\hline Mental disorders & $2.6 \%$ & $3.5 \%$ \\
\hline Nervous system & $2.2 \%$ & $2.3 \%$ \\
\hline Myocard infarction & $10.4 \%$ & $9.6 \%$ \\
\hline Stroke & $8.8 \%$ & $8.8 \%$ \\
\hline Other circulatory & $17.6 \%$ & $16.9 \%$ \\
\hline Pneumonia & $4.1 \%$ & $4.6 \%$ \\
\hline Asthma and COPD & $5.2 \%$ & $4.8 \%$ \\
\hline Digestive tract & $3.7 \%$ & $3.6 \%$ \\
\hline Musculoskeletal system & $0.6 \%$ & $0.6 \%$ \\
\hline Urinary tract & $2.2 \%$ & $1.9 \%$ \\
\hline Injuries & $2.6 \%$ & $2.4 \%$ \\
\hline All other causes & $6.4 \%$ & $9.5 \%$ \\
\hline
\end{tabular}

${ }^{a}$ OECD SHA: HF 1.2 (social security), HF 2.1/2.2 (private and social health insurance), HF 2.3 (consumer households: additional contributions and out-ofpocket payments).

${ }^{\mathrm{b}}$ For 16,702 decedents the cause of death was known.

Due to data difficulties we had to exclude the third compartment $(10.6 \%$ of expenditure mainly consisting of co-payments and out-of-pocket expenses for eyeglasses and dental care), mental health and substance abuse hospitals $(6.9 \%)$, costs of administration, public health programmes as far as financed by health insurance and some residential facilities (other than the above mentioned homes for elderly and persons with intellectual disabilities).

\section{Study group}

We used health insurance data regarding expenditures for the second compartment of the health care system for 2.1 million inhabitants, representing $13.4 \%$ of the whole Dutch population in 1999 (Table 1). The sample was retrieved by Vektis, the statistical office of health insurance companies in the Netherlands, and covered different urban and rural areas. The data set contained information on patient date of birth, sex, date of death and health expenditure on general practitioners, hospitals, drugs and all other services belonging to this compartment of the health care system. We used information for all persons who were insured during the whole period in 1998 and 1999. Newborn children and other people who joined the included insurance schemes within this period were omitted as well as people who had them removed from these schemes for other reasons than death.

We linked these files at individual level, using birth date, sex and zip-code, with data for the first compartment regarding home care (covering $100 \%$ of all home care in the Netherlands and gathered by the statistical office for long-term care) 
and nursing homes (covering $65 \%$ of the users of nursing home care according to the nursing home registry).

Subsequently we linked this sample with official mortality figures from Statistics Netherlands. We validated the date of death and were able to determine the cause of death for 16,702 decedents in 1999.

Table 1 provides some key characteristics of our data set. We included 2.1 million inhabitants of which $66.5 \%$ was insured by social health insurance and $33.5 \%$ by private health insurance, more or less in line with the corresponding distribution among the population. Since we excluded newborn children and people who changed insurance company, mainly employees as a consequence of specific rules in the Dutch finance system, the younger age groups were underrepresented. Due to the proportionally higher number of elderly our data set contained comparatively more women and more decedents. We found a mortality rate of $1.15 \%$ compared to $0.89 \%$ in the population. The difference, however, could be fully explained by the different age structure.

Table 1 also shows that the study group is representative for the Dutch population regarding age and cause of death. Most people died from cancer and circulatory diseases.

\section{Cost calculation and projection}

Health care costs were calculated in two ways. For the second compartment (cure) we used billed insurance costs. Costs of home care and nursing homes were based on resource use and corresponding unit costs.

For decedents in 1999 we calculated health expenditure in the 365 days prior to death. For privately insured decedents $(33.5 \%$ of the sample, Table 1$)$ we had information on the date of death and total expenditure for the individual years 1998 and 1999 as well as the exact health expenditures during the last year of life. So we were able to calculate the fraction of costs in 1998 belonging to the last year of life. Depending on the month of death we distinguished 11 groups.

For persons with a social health insurance plan we knew the date of death and total expenditure in 1999 and 1998. We calculated the costs in the last year of life by interpolating the 1998 data on a monthly basis with the above-mentioned fraction, assuming that the distribution of costs within the last year of life is comparable for both groups.

For survivors we had information on health expenditure in 1999. Some of these people died in 2000, and therefore the survivor data included some mortality costs as well. We corrected expenditure data per age-sex group using mortality rates and health care costs in the last year of life assuming that on average people died halfway through the year, attributing half of the mortality costs to 1999 and the other half to 2000 . Since costs also increase during the last year of life, this might have resulted in a small overcorrection.

For the calculation of average costs for all decedents and survivors we weighed the sample by the age-sex distribution in the population.

We used life tables (Siegel \& Swanson, 2004) for the Dutch population (Statistics Netherlands, 2005) to estimate expected lifetime health care costs from birth until death according to mortality rates in 1999 and 2020. Using population 
forecasts of Statistics Netherlands (de Jong, 2003) in a simple cohort-component method (Serup-Hansen, Wickstrom, \& Kristiansen, 2002) we made projections of future health expenditure. We distinguished four effects. First, the influence of population growth. Second, the influence of changing size of birth cohorts, mainly consisting of the effect of the ageing baby-boom generation on health expenditure. Third, the influence of changing mortality resulting in higher life expectancy and higher health expenditure for survivors. Fourth, the influence of changing mortality resulting on average in a postponement of death by which total mortality costs are likely to decrease.

\section{Results}

Health care costs in the last year of life of people who died in 1999 were on average 13.5 times higher than costs of people who did not die $(14,906$ and 1102 Euro, respectively). Gender differences were small and statistically not significant (men 14,761 Euro, women 15,044 Euro), but costs differed greatly for individual decedents (standard deviation 18,751 Euro).

Most costs in the last year of life were made in hospitals including the costs of medical specialists $(54 \%)$, followed by nursing homes $(19 \%)$, pharmaceutical care $(7 \%)$ and home care $(7 \%)$. The contribution of general practitioners was limited to $1 \%$ of the costs.

\section{Causes of death}

Costs differed for the various causes of death. Costs of heart attacks and injuries were relatively low (Table 2 ), due to the unexpected character and high fatality of these events. Among the most frequent causes of death costs were highest for cancer, with substantial variation from liver cancer (14,216 Euro) to neoplasms of lymphatic and hematopoietic tissue (26,712 Euro). Costs of stroke and other cardiovascular diseases held intermediate positions, due to low costs for people who died immediately or very soon and high costs for the others who needed a lot of care during a longer period. Costs were highest for diseases of the urinary tract, infectious diseases and musculoskeletal diseases.

\section{Table 2.}

Health care costs ${ }^{a}$ in the last year of life by gender and cause of death. Average costs per decedent in Euro. Total costs for all decedents in 1999 (million Euro, share in \%)

\begin{tabular}{|l|l|l|l|l|l|}
\hline & \multicolumn{4}{|l|}{ Average costs per decedent } & \multicolumn{2}{l|}{ Total costs (whole population) } \\
\hline & Men & Women & Total & C1 mln & $\%$ \\
\hline Infectious diseases & 24,884 & 18,072 & 21,698 & 35.5 & 1.7 \\
\hline Cancers & 17,835 & 19,679 & 18,669 & 730.5 & 35.3 \\
\hline Diabetes & 17,034 & 19,002 & 18,280 & 60.5 & 2.9 \\
\hline Mental disorders & 13,095 & 11,997 & 12,341 & 61.0 & 2.9 \\
\hline Nervous system & 20,978 & 13,950 & 17,088 & 54.8 & 2.6 \\
\hline Myocard infarction & 7256 & 9074 & 8068 & 108.6 & 5.2 \\
\hline Stroke & 14,181 & 13,461 & 13,747 & 170.6 & 8.2 \\
\hline
\end{tabular}


Social Science \& Medicine Volume 63, Issue 7 , October 2006, Pages 1720-1731

\begin{tabular}{|l|l|l|l|l|l|}
\hline & \multicolumn{4}{|l|}{ Average costs per decedent } & \multicolumn{2}{l|}{ Total costs (whole population) } \\
\hline & Men & Women & Total & C1 mln & $\%$ \\
\hline Other cardiovascular & 12,732 & 12,452 & 12,586 & 298.6 & 14.4 \\
\hline Pneumonia & 15,934 & 12,560 & 13,954 & 90.5 & 4.4 \\
\hline Asthma and COPD & 15,888 & 19,163 & 17,126 & 115.4 & 5.6 \\
\hline Digestive tract & 16,617 & 16,491 & 16,543 & 84.1 & 4.1 \\
\hline Musculoskeletal system & 22,459 & 19,800 & 20,686 & 18.9 & 0.9 \\
\hline Urinary tract & 25,047 & 20,015 & 22,211 & 60.8 & 2.9 \\
\hline Injuries & 7897 & 10,747 & 9400 & 31.4 & 1.5 \\
\hline Other & 10,013 & 12,017 & 11,193 & 149.7 & 7.2 \\
\hline Total & 14,761 & 15,044 & 14,906 & 2070.8 & 100.0 \\
\hline
\end{tabular}

a Somatic care, nursing homes and home care.

In spite of this differences we also found that there was much more variation in costs between people dying from a certain disease than across the different causes of death. Health care needs and health care costs, therefore, apparently were induced by proximity to death rather than the ultimate cause of death.

At national level these figures implied total estimated cost of 2.1 billion Euro for all decedents together. Our analysis showed that $35.3 \%$ of these expenditure regarded people who died of cancer ( $27.9 \%$ of all decedents), $8.2 \%$ related to stroke ( $8.8 \%$ of the decedents), $5.2 \%$ to people dying of a myocard infarction $(9.6 \%)$ and $14.4 \%$ related to other circulatory diseases $(16.9 \%$ of the decedents). Together these major causes of death represented $63.2 \%$ of the decedents and almost the same percentage of their health expenditure in the last year of life.

\section{Age}

Health care costs in the last year of life also depended on age (Fig. 1). Costs were high for people dying at comparatively younger ages ( $<70$ years), and turned out to decrease with increasing age of death, mainly due to a decrease in hospital care. 


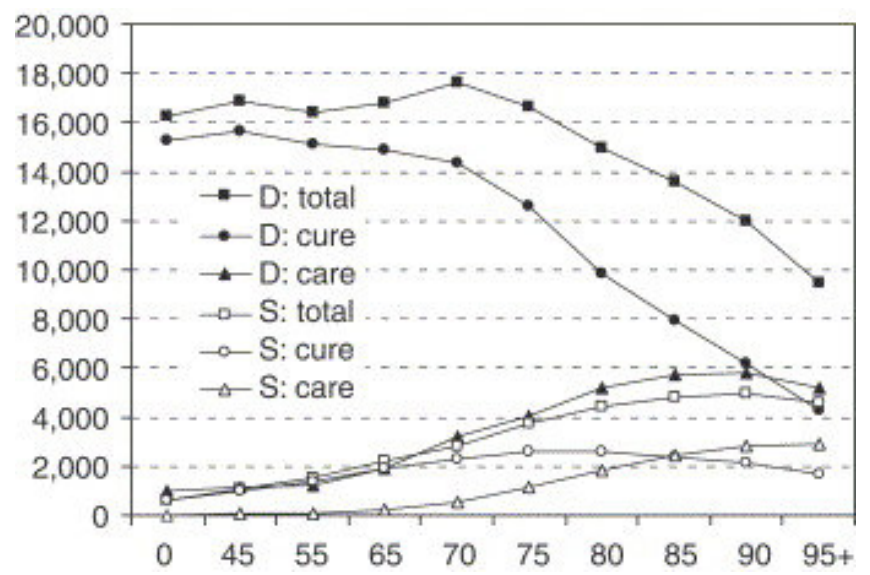

Fig. 1. Average health care costs (in Euro) for decedents (D) in their last year of life and for survivors (S) in 1999, by age and type of care (cure: general practitioners, hospitals, drugs and other services of the second compartment in Dutch health care, versus care: nursing homes and home care).

This pattern more or less mirrored the age pattern of surviving people: costs increasing with age. Fig. 1 shows some remarkable differences between cure and care. For cure (second compartment in the Dutch health care system) the age pattern of average costs is opposite for survivors and decedents although costs for decedents were much higher at all ages, while for care the age pattern for survivors and decedents is almost the same, again with higher levels for decedents.

Given these patterns the cost-ratio between decedents and survivors depends heavily on age. Fig. 2 shows a declining curve for both men and women, with almost 30 times higher costs for people dying at younger ages and a ratio less than 5 for decedents of 70 years and older. For women in age groups 45-65 we found a relatively high ratio compared to men. This was caused by higher costs for female decedents rather than lower costs for survivors. As Fig. 3 shows this pattern was found for all causes of death, mainly cancer, diabetes and diseases of the urinary tract (the latter ones included in 'other causes'). As a result the declining age pattern was more prominent for women than for men. This figure also demonstrates remarkable differences between the various causes of death. Costs for cancer experienced a strong decline at younger ages, both for men and women that due to the high mortality rate dominated the overall age pattern. Other causes of death show a more or less inversed u-shaped curve: for younger decedents costs increased with increasing age of death, while they declined for people dying at ages of 70 years and older. Finally, for circulatory diseases Fig. 3 displays lower costs and less variation between the different age groups, especially among men. 


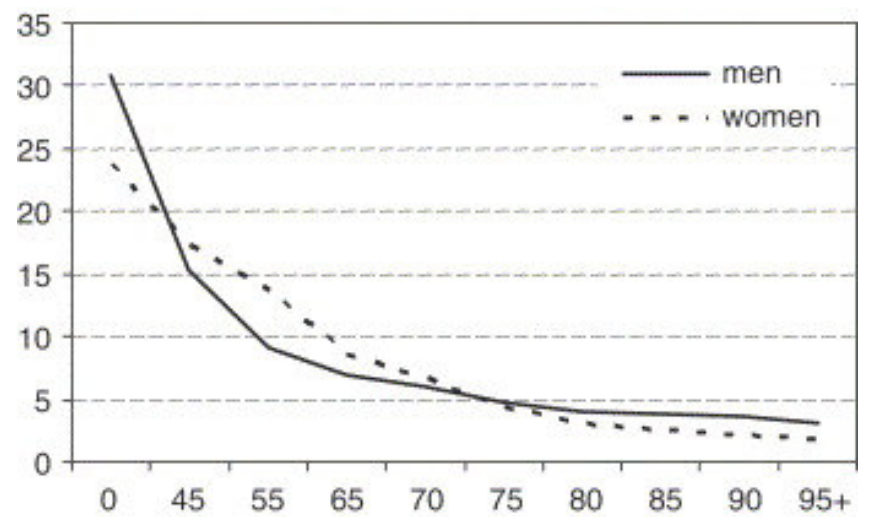

Fig. 2. Ratio between average health care costs in the last year of decedents and average costs of survivors by age and sex, 1999.
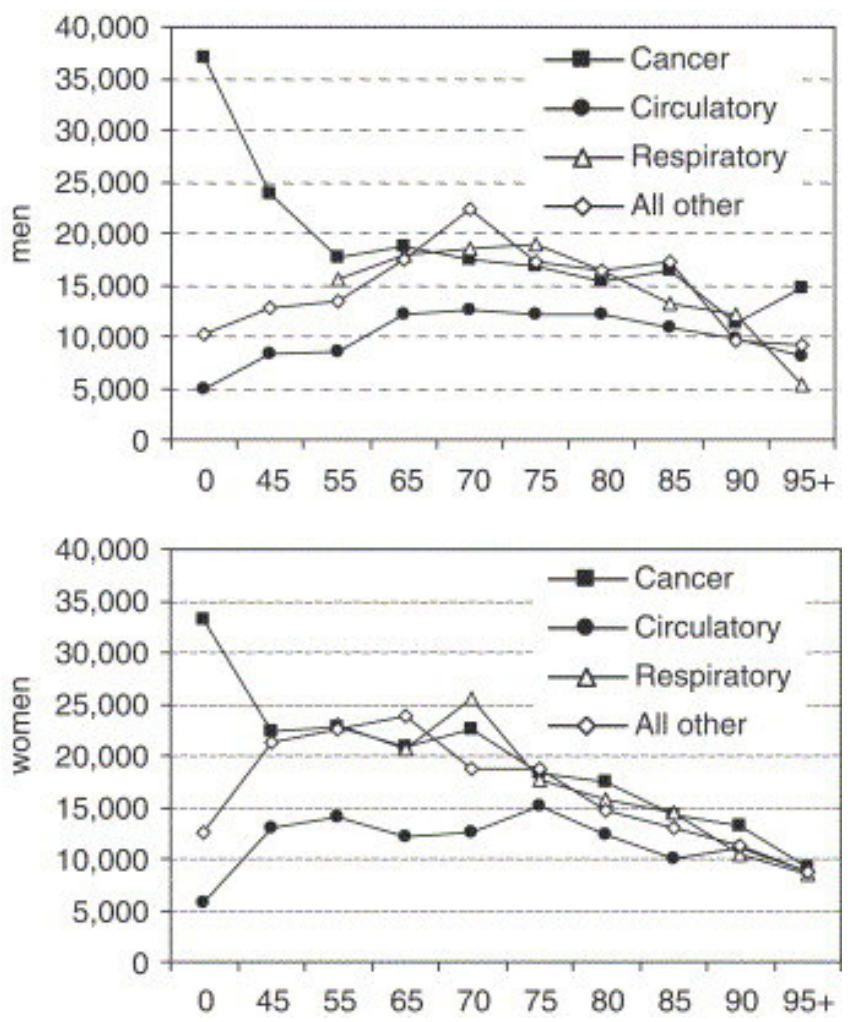

Fig. 3. Average health care costs (in Euro) in the last year of life for people who died in 1999, by age and cause of death.

\section{National health expenditure}

In 1999 the Netherlands counted 15.8 million inhabitants of whom 140,487 persons died $(0.89 \%$, Table 1$)$. Given the age profiles of health expenditure for decedents and survivors total costs of people in their last year of life amounted to 2.1 billion euro (11.1\% of total expenditure on included services). The largest part by far of health expenditure is therefore related to morbidity rather than to mortality. As Fig. 4 demonstrates, for most age groups the share of the decedents in total health expenditure was negligible. From age 65 onwards the importance increased due to increasing mortality. The lower panel of Fig. 4 
demonstrates that among the elderly ( $>65$ years) the percentage of total expenditure on mortality increased from $12.2 \%$ until $56.7 \%$ with increasing age, with considerable differences between men and women.
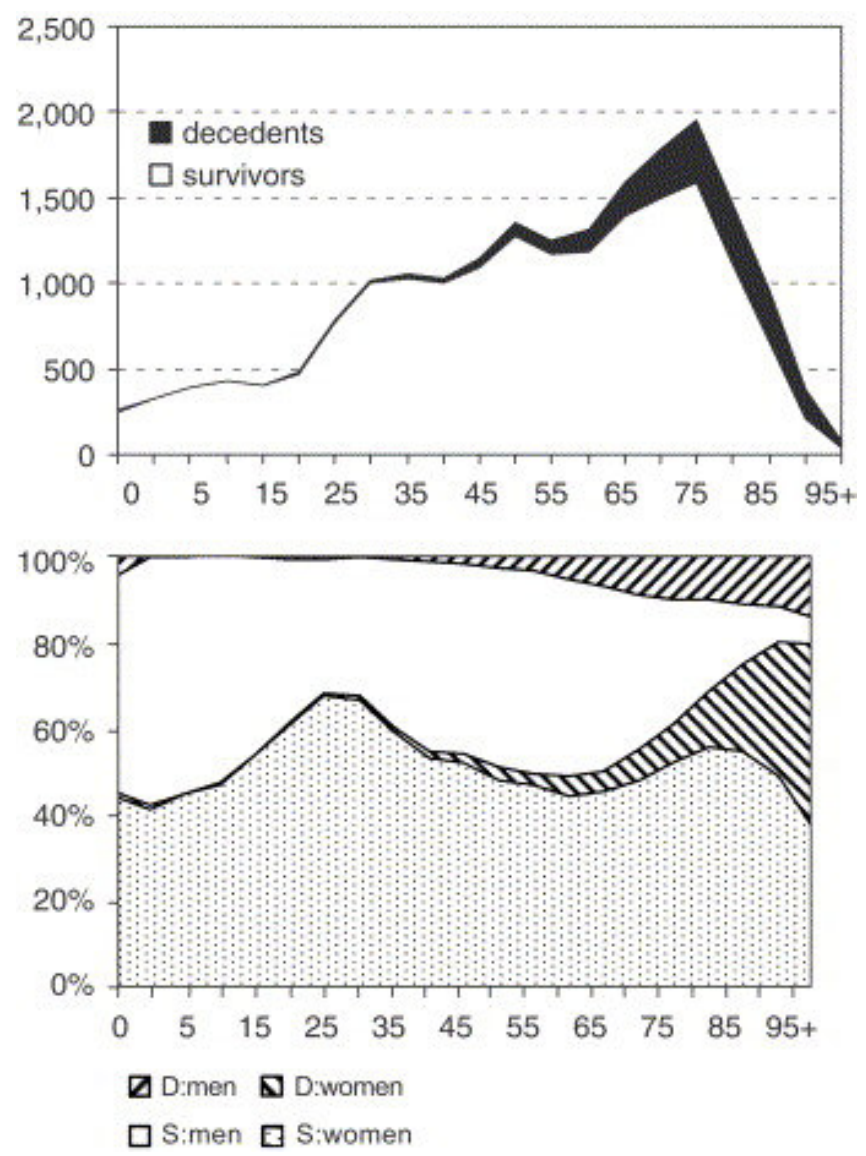

Fig. 4. Total health expenditure in the Netherlands for decedents and survivors in 1999 (upper panel: costs in million Euro, lower panel: share of decedents and survivors in total costs per age group for men and women).

\section{Expected lifetime costs}

The detailed cost figures by age and gender, both for survivors and decedents, enabled us to estimate expected lifetime health care costs. In 1999 life expectancy at birth among men was 75.1 years. Using a life table we estimated the corresponding life time costs at 94,233 Euro (Table 3). For women, both life expectancy and lifetime costs were higher (126,536 Euro). 


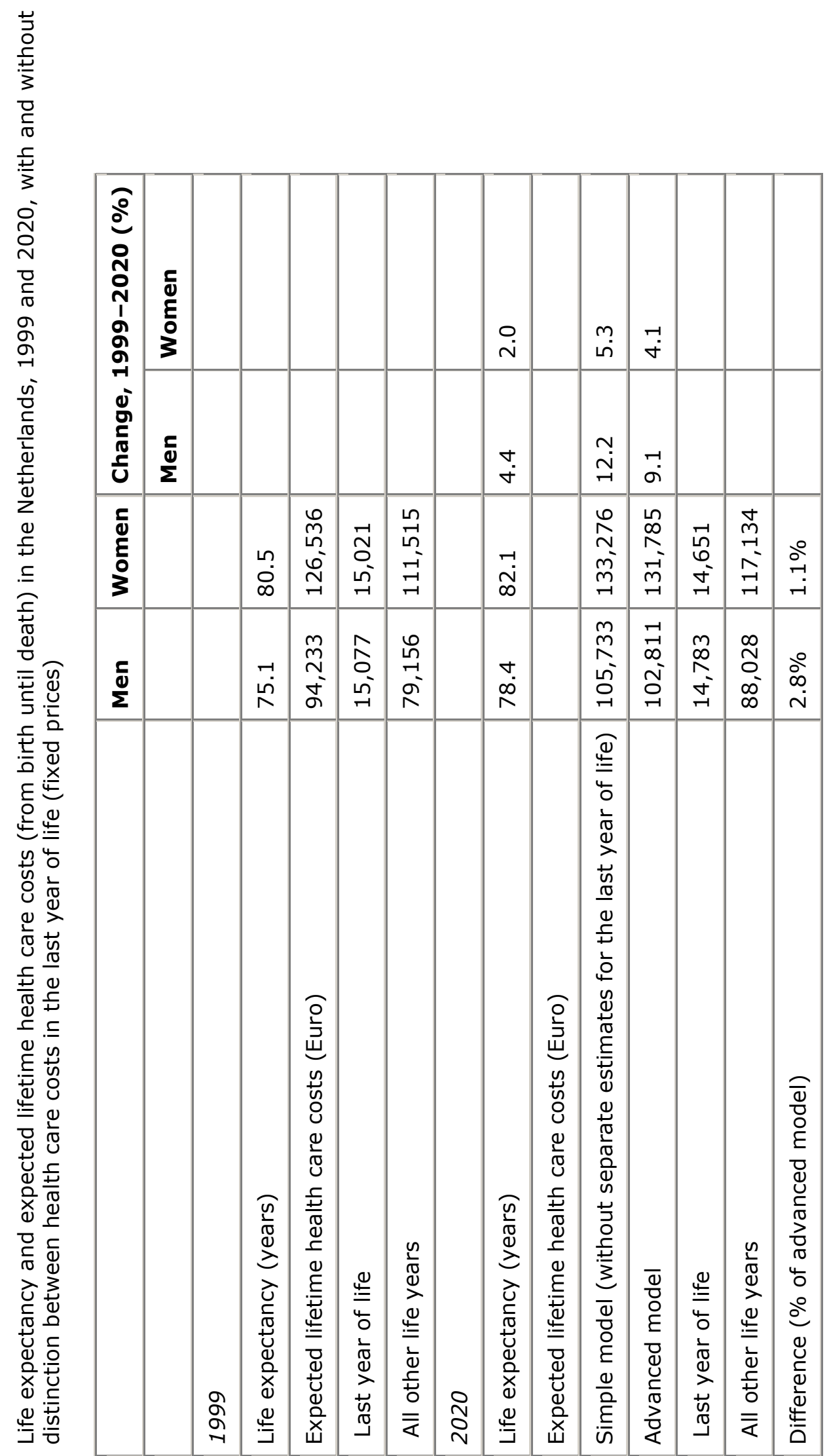


Due to improving longevity life expectancy will increase in the next decades by $4.4 \%$ and $2.0 \%$ for men and women respectively, and cause an increase in expected lifetime health care costs. If we apply a simple model that does not adjust for the different costs in the last year of life, the expected life time costs will increase by $12.2 \%$ for men and $5.3 \%$ for women in the period $1999-2020$.

We also applied a more advanced model in which lifetime expected costs comprised different estimates for the last year of life and all other years. In this model expected lifetime costs also increase, but less than in the simple model ( $9.1 \%$ and $4.1 \%$ for men and women, respectively). Given the supremacy of the advanced model, the simple model overestimated lifetime costs by $2.8 \%$ for men and $1.1 \%$ for women.

\section{Demographic cost projections}

According to demographic forecasts of Statistics Netherlands the Dutch population will increase to 16.8 million in 2020 . More inhabitants imply higher health care costs. With all other factors fixed we estimated that in 1999-2020 health care supply needs an $0.29 \%$ annual increase to maintain the care on the levels of 1999 (Table 4). Price developments will be additional. Since the expansion of the population also implies an increase of the labour force and the GDP this part of increasing health expenditure is neither important nor a problem.

\section{Table 4.}

Projections of future health expenditure ${ }^{a}$ in the Netherlands in 1999-2020 based on demographic changes (annual growth rate in \%, fixed prices), according estimates without (simple model) and with the influence of costs in the last year of life (advanced model)

\begin{tabular}{|c|c|c|c|c|c|c|}
\hline & \multirow[t]{2}{*}{ Men } & \multirow[t]{2}{*}{ Women } & \multirow[t]{2}{*}{ Total } & \multicolumn{3}{|c|}{ Annual change (\%) } \\
\hline & & & & Men & Women & Total \\
\hline \multicolumn{7}{|l|}{ Population (million) } \\
\hline 1999 & 7.8 & 8.0 & 15.8 & & & \\
\hline 2020 & 8.3 & 8.5 & 16.8 & 0.27 & 0.31 & 0.29 \\
\hline \multicolumn{7}{|l|}{ Simple model } \\
\hline \multicolumn{7}{|c|}{ Total health expenditure (million euro) } \\
\hline 1999 & 8296 & 11,123 & 19,419 & & & \\
\hline 2020 & 10,767 & 13,147 & 23,913 & 1.25 & 0.80 & 1.00 \\
\hline \multicolumn{7}{|c|}{ Per capita health expenditure (euro) } \\
\hline 1999 & 1061 & 1392 & 1228 & & & \\
\hline \multicolumn{7}{|l|}{ Change: } \\
\hline Ageing of baby-boom cohort & 107 & 75 & 91 & 0.46 & 0.25 & 0.34 \\
\hline Improved longevity & 132 & 76 & 104 & 0.56 & 0.25 & 0.39 \\
\hline 2020 & 1301 & 1543 & 1423 & 0.97 & 0.49 & 0.71 \\
\hline
\end{tabular}




\begin{tabular}{|l|l|l|l|l|l|l|}
\hline & Men & Women & \multicolumn{2}{l|}{ Total } & \multicolumn{3}{l|}{ Annual change (\%) } \\
\hline & & & & Men & Women & Total \\
\hline Advanced model & & & & & & \\
\hline Total health expenditure & & & & & \\
\hline 1999 & 8296 & 11,123 & 19,419 & & & \\
\hline 2020 & 10,468 & 12,992 & 23,459 & 1.11 & 0.74 & 0.90 \\
\hline Per capita health expenditure & & & & & & \\
\hline 1999 & 1061 & 1392 & 1228 & & & \\
\hline Change: & & & & & & \\
\hline Ageing of baby-boom cohort & 107 & 75 & 91 & 0.46 & 0.25 & 0.34 \\
\hline Improved longevity & 100 & 62 & 81 & 0.43 & 0.21 & 0.30 \\
\hline Increased age at death & -3 & -4 & -4 & -0.01 & -0.01 & -0.01 \\
\hline 2020 & 1264 & 1525 & 1396 & 0.84 & 0.44 & 0.61 \\
\hline Difference advanced/simple model & & & & & & \\
\hline (\% change in growth rate) & & & & & & -13.0 \\
\hline Total expenditure & & & & -10.9 & -7.1 & -9.3 \\
\hline Per capita expenditure & & & & & & \\
\hline Longevity only & & & & & & \\
\hline
\end{tabular}

a Including general practitioners, hospitals, drugs and other services of the second compartment in Dutch health care (cure) and nursing homes and home care.

All other factors, however, are not fixed and will change as well. We focussed on ageing and its influence on average per capita costs. We distinguished two models: a simple model based on fixed per capita costs in each age-gender group, and a more advanced model in which age-gender specific costs were adjusted for costs in the last year of life in combination with changing mortality rates.

According to the simple model per capita health care costs will increase until 2020 by $0.71 \%$ per year, with remarkable differences between men and women. Two factors are important: first, the baby-boom generation will get to ages with higher health care use. Second, improvements in longevity will result in a higher average age. In the advanced model the latter effect is split up into two components: additional life years with lower average costs per age category compared to the simple model, and postponement of death. As Table 4 shows, this distinction had a significant influence on the cost projection. In the advanced model per capita costs will increase by $0.61 \%$ per year. The difference with the simple model resulted from sizeable lower cost for improved longevity and a small declining effect on costs in the last year of life. Resulting from this total costs in the advanced model were estimated to increase by an annual rate of $0.90 \%$, again with important gender differences. This figure implies that the development in total health expenditure will abate by $9.3 \%$ of the growth rate in the simple 
model. The deviation in the development of per capita costs is even more $(-13.0 \%)$. For the isolated effect of improved longevity only, the deviation is highest $(-25.8 \%)$.

From this projections it is quite clear that health care costs during the last year of life do matter, and have considerable influence on projections of future health care costs.

\section{Discussion}

In this paper we contribute to the 'red herring' debate about the role of health care costs in the last year of life (Seshamani \& Gray, 2004; Steinmann, Telser, \& Zweifel, 2005; Zweifel et al., 1999). We confirmed for the Dutch situation the validity of conclusions by other authors that 'health care costs during the last year of life matter' (Serup-Hansen et al., 2002) so that 'it is time to include time to death' (Stearns \& Norton, 2004).

\section{Strengths and weaknesses}

Our study has some major advantages. Whereas most other studies focussed on the elderly population (mostly 65 years and older) (McGrail et al., 2000; Lubitz, Beebe, \& Baker, 1995; Stearns \& Norton, 2004; Seshamani \& Gray, 2004; Yang, Norton, \& Stearns, 2003; Zweifel et al., 1999), our sample covered all age groups from birth to death. Second, we used a very large and representative sample (13\% of the population), retrieved from health insurance files and including persons with zero costs, that allowed for detailed comparisons between decedents and survivors. Third, an advantage over nearly all other studies is that we linked cost data to the official mortality register and were able to analyse cost differences between the various causes of death. Fourth, we included all normal, necessary medical care: physicians, hospitals, drugs and related services, and furthermore expenditure on nursing homes and home care, whereas most other studies focussed on hospital care.

A weakness might be that we had to exclude residential care facilities for the elderly and people with intellectual disabilities. The OECD, however, does not consider both services as a part of the health care system. Furthermore, expenditure on intellectual disability is high and almost stable during the course of life independent from the time to death. From an international perspective as documented in the OECD System of Health Accounts our analysis is mainly missing expenditure on out-of-pocket expenses (among others for eyeglasses and dental care), mental health care, some residential facilities and health care administration. For the greater part, however, this expenditure has no relation with health care in the last year of life. Inclusion would result in a lower percentage of death-related costs. Nevertheless, it is a pity that we were not able to include at least expenditure on mental health care in our analysis, even though our sample covered more services than most other studies.

Another weakness might by that we did not employ complex econometric models as for instance Zweifel et al. (1999), Steinmann et al. (2005), Seshamani and Gray (2004), Breyer and Felder (2004) and Stearns and Norton (2004). As Yang et al. (2003) stated, however, descriptive analyses can provide strong evidence, and Serup-Hansen et al. (2002), who also used a cohort-component model, argued that 'more sophisticated models or techniques do not provide more accurate forecasts than simple techniques'. Our approach based on a cohortcomponent method in combination with life tables, therefore, has indeed some advantages. First, we avoided econometric problems as the endogeneity between 
date of death and the health services used in the last year of life (Seshamani \& Gray, 2004; Steinmann et al., 2005). Second, our approach in combination with a cross-sectional sample covering all age groups allowed for a complete separation of the different demographic influences on future health expenditure.

\section{Health care costs in the last year of life}

We estimated that $11.1 \%$ of total expenditure of the included health services could be assigned to people in their last year of life. This percentage is consistent with the findings of Stooker et al. (2001) although they used a smaller and nonrandom sample. Lubitz and Riley (1993) reported a much higher figure (27.2$30.6 \%$ ) for the United States in the period 1976-1988, and Felder (1997) mentioned that 'in western industrialised countries, about $30 \%$ of health-care expenditure is incurred by individuals in their last year of life'. Since both studies focussed on the elderly population and our sample covered all age groups the difference might be explained by the different age range. If we neglect the younger age groups our study shows a comparable figure of $26.1 \%$ for the retired Dutch population (65 years and older, Fig. 4). This seems in line with Emanuel (1996) who stated that 'Medical care at the end of life consumes $10-12 \%$ of the total health care budget and $27 \%$ of the Medicare budget'.

As most other authors we found an inverse relationship between health care costs in the last period of life and age at death. Only Breyer and Felder (2004) and McGrail et al. (2000) demonstrated increasing costs for Germany and Canada, respectively. McGrail, however, included only the last 6 months of life and showed that for this period the increase in nursing and social care costs dominated a decrease in medical costs. In the same manner Yang et al. (2003) revealed more or less constant costs for the United States, consisting of decreasing Medicare expenditure and increasing Medicaid expenditure. So from these and all other studies there is strong evidence that expenditure in the last year of life on hospitals, cure or necessary medical services, or whatever it maybe called, declines with increasing age at death.

Our figures demonstrated that in the Netherlands people who died in 1999 at age of $95+$ consumed about $30 \%$ of curative services (general practitioners, hospitals, drugs and some other services) compared to people who died in age group 65-70 years.

Serup-Hansen et al. (2002) showed a comparable figure for Denmark in 1995. Brockmann (2002) estimated smaller decreases for Germany (43-47\%), while for the United States percentages of about $40 \%$ and $52 \%$ were shown by Lubitz and Riley (1993) and Perls (1997), respectively.

We found an average cost ratio between decedents and survivors of 13.5 with a broad range (from 30 until less than 5) due to a strong inverse relation with age. This ratio is high compared to Zweifel et al. (1999), who demonstrated an overall ratio of 10.6 in 1982 that dropped to 5.3 in 1992, and a ratio for the elderly that dropped from 5.6 to 3.7 in the same period. Our findings, however, are in line with that of other authors as McGrail et al. (2000) who found a range of 8.4-2.5 for the Canadian population of 75 years and older, and Serup-Hansen et al. (2002) who estimated ratios of 9.4 and 13.3 Danish men and women, respectively, and a range of 26.6-2.3 for women aged 50-54 and 90-94, respectively.

It is obvious that country and study-specific characteristics hamper cross-national comparisons (Seshamani \& Gray, 2003). Nevertheless, the main findings are 
quite robust: higher costs in the last year of life and an inverse relation with age of death. An important issue for future research is why the slope of the cost curve differs among countries. This topic is related to the debate on aggressiveness of care (Perls, 1997), differences in medical decision making and more or less implicit rationing among the elderly as suggested by Brockmann (2002). A special issue here is the role of end-of-life decision-making. Van der Heide et al. (2003) have shown that in $44 \%$ of all deaths in the Netherlands end-of-life decisions are made. They found that non-treatment decisions-that is, decisions to withhold or withdraw potentially life-prolonging treatments-were made in $20 \%$ of all deaths in the Netherlands. Other end-of-life decisions regarded doctor assisted dying $(3.4 \%)$ and alleviation of pain and symptoms with possible life-shortening effect $(20 \%)$.

These figures are more or less comparable to other European countries, Italy excepted, but compared to the United States in the Netherlands non-treatment decisions are much more common.

Because our data did not allow for studying the relationship between nontreatment decisions and health care costs, additional research is required to address the question whether or not cross-national differences in health care costs in the last year of life depend on differences in end-of-life decisions. That research should also address the endogeneity argument raised by Seshamani and Gray (2004), meaning that health expenditures are affected by remaining time to death and in turn affect time to death, and should also examine the statement of Emanuel and Emanuel (1994) that cost savings at the end of life are an illusion.

\section{Projections of future health care costs}

The main objective of the 'red herring' debate is to demonstrate that standard projection methods that use fixed costs per age-gender group will overestimate the effects of ageing on future health expenditure. Since the seminal paper of Zweifel et al. (1999) several studies confirmed this idea, although the overall effect was not quantified in some major studies (Stearns \& Norton, 2004; Seshamani \& Gray, 2004; Yang et al., 2003).

Our approach and sample, including decedents as well as survivors of all ages, allowed for quantification of four demographic influences: (1) population growth; (2) changing cohorts mainly due to the ageing of the baby boom generation; (3) improved longevity and costs in life years gained; and (4) postponement of death.

In our more advanced model the estimated growth rate of health expenditure is substantially lower compared to standard projection methods $(-9.3 \%$ for total expenditure, $-13.0 \%$ for per capita expenditure and $-25.8 \%$ if only the effect of increased longevity and postponement of death were taken into account). These figures may be compared with results from other studies. Serup-Hansen et al. (2002) found a decrease from $18.5 \%$ to $15.1 \%$ for a 25 -year period. On annual basis this corresponds with a decrease of $17.2 \%$. Focussing on changes in 'age structure' Breyer and Felder (2004) demonstrated a decrease of $16.6-34.7 \%$ for the German population in 2002-2020. Steinmann et al. (2005) mentioned a decreasing rate from $0.5 \%$ to $0.37 \%$ per year $(-26.0 \%)$ for Switzerland in $2005-$ 2060. They also demonstrated that this average difference is subject to considerable variation over time and concluded that institutional characteristics of health care systems play an important role. This latter conclusion might be read as a warning against a simple comparison of detailed figures from different countries. Nevertheless it is clear that the 'red herring' hypothesis proofed to be 
valid for the Netherlands in continuation of comparable studies for other Western countries.

Since the 'red herring effect', however, is rather limited and several other factors influence cost development in health care, it must be fair to conclude that simple demographic projections have their own worth, not at least because they need less complicated and regularly available data.

\section{Causes of death}

It is striking that most contributions to the 'red herring' debate did not analyse the role of causes of death. Although we demonstrated that time to death seems more important than the ultimate cause of death, we also showed some important differences between the major causes of death, namely the higher expenditure and different age pattern of expenditure on people dying of cancer compared to heart disease. These findings were consistent with studies of Riley et al. (1987) and Brockmann (2002), and may have consequences for the cost development in an ageing society. Since the cost projections are based on the average costs in the last year of life that decline with age, they neglect the cause and costs of mortality reduction. Our figures demonstrate that a shift from circulatory disease to other causes of death comes at the price of higher expenditure on those diseases, yet apart from the costs of attaining the mortality reduction for heart diseases.

It is important, therefore, to conclude that future expenditures are affected by a lot of other factors. The 'red herring' debate can improve on at least four topics. First, the causes and costs of longevity increases have to be studied and incorporated in the cost projections. Second, the changes in disease-specific mortality rates and their influence on health care costs in the last year of life should be estimated. Third, time trends in costs in the last year of life must be analysed, including the effects of the endogeneity problem and changing opinions on end of life decisions in health care. Fourth, trends in costs of surviving should be studied. Lubitz et al. (2003) demonstrated that in the United States the expected cumulative health expenditures of the healthier elderly persons, despite their greater longevity, were similar to those for less healthy persons. If this finding has validity across the world, the demographic influence on health expenditure will only consist of population growth and changing birth cohorts. Since Lubitz et al. (2003), however, only included Medicare expenditure and thus neglected nursing homes and other long term care facilities, their conclusions will not hold for total health expenditure.

Nevertheless, we conclude that Western societies should not worry about the effects of ageing. Since other factors as technological change and increasing service levels have much more influence on the cost development in health care, policy makers should focus on the creation of a sustainable health care system that can meet the health care needs of the baby boom generation.

\section{Acknowledgements}

The authors gratefully acknowledge Jean Takken for assistance with data collection and Agnes van der Heide and two anonymous reviewers for useful comments. 


\section{References}

Breyer \& Felder (2004) Breyer, F., \& Felder, S. (2004). Life expectancy and health care expenditures in the 21st century: A new calculation for Germany using the costs of dying. Berlin: German Institute for Economic Research (DIW Berlin).

Brockmann (2002) H. Brockmann, Why is less money spent on health care for the elderly than for the rest of the population? Health care rationing in German hospitals, Social Science and Medicine $\mathbf{5 5}$ (2002) (4), pp. 593-608.

Emanuel (1996) E.J. Emanuel, Cost savings at the end of life. What do the data show?, Journal of American Medical Association 275 (1996) (24), pp. 1907-1914.

Emanuel \& Emanuel (1994) E.J. Emanuel and L.L. Emanuel, The economics of dying. The illusion of cost savings at the end of life, New England Journal of Medicine 330 (1994) (8), pp. 540-544.

Exter, Hermans, Dosljak, \& Busse (2004) A. Exter, H. Hermans, M. Dosljak and R. Busse, Health care systems in transition: Netherlands, WHO Regional Office for Europe on behalf of the European Observatory on Health Systems and Policies, Copenhagen (2004).

Felder (1997) S. Felder, Costs of dying: Alternatives to rationing, Health Policy 39 (1997) (2), pp. 167-176.

de Jong (2003) A. de Jong, Bevolkingsprognose 2002-2050: Anderhalf miljoen inwoners erbij, CBS Bevolkingstrends 51 (2003) (1), pp. 21-26.

Liu \& Yang (2002) C.N. Liu and M.C. Yang, National health insurance expenditure for adult beneficiaries in Taiwan in their last year of life, Journal of the Formosan Medical Association 101 (2002) (8), pp. 552-559.

Lubitz, Beebe, \& Baker (1995) J. Lubitz, J. Beebe and C. Baker, Longevity and Medicare expenditures, New England Journal of Medicine 332 (1995) (15), pp. 999-1003.

Lubitz, Cai, Kramarow, \& Lentzner (2003) J. Lubitz, L. Cai, E. Kramarow and H. Lentzner, Health, life expectancy, and health care spending among the elderly, New England Journal of Medicine $\mathbf{3 4 9}$ (2003) (11), pp. 1048-1055.

Lubitz, Greenberg, Gorina, Wartzman, \& Gibson (2001) J. Lubitz, L.G. Greenberg, Y. Gorina, L. Wartzman and D. Gibson, Three decades of health care use by the elderly, 1965-1998, Health Affairs (Millwood) 20 (2001) (2), pp. 19-32

Lubitz \& Riley (1993) J.D. Lubitz and G.F. Riley, Trends in Medicare payments in the last year of life, New England Journal of Medicine 328 (1993) (15), pp. 1092-1096.

Lunney, Lynn, \& Hogan (2002) J.R. Lunney, J. Lynn and C. Hogan, Profiles of older medicare decedents, Journal of American Geriatric Society 50 (2002) (6), pp. 1108-1112.

McGrail et al. (2000) K. McGrail, B. Green, M.L. Barer, R.G. Evans, C. Hertzman and C. Normand, Age, costs of acute and long-term care and proximity to death: Evidence for 1987-88 and 1994-95 in British Columbia, Age Ageing 29 (2000) (3), pp. 249-253.

Meerding, Bonneux, Polder, Koopmanschap, \& van der Maas (1998) W.J. Meerding, L. Bonneux, J.J. Polder, M.A. Koopmanschap and P.J. van der Maas, Demographic and epidemiological determinants of health care costs in the Netherlands: Cost of illness study, British Medical Journal 317 (1998), pp. 111-115.

van Mosseveld \& Smit (2005) C.J. P.M. van Mosseveld and J.M. Smit, Health and social accounts 1998-2003: Working paper, Statistisc Netherlands, Voorburg (2005).

OECD (2000) OECD, A system of health accounts, OECD/CREDES, Paris (2000). 
O'Neill, Groom, Avery, Boot, \& Thornhill (2000) C. O'Neill, L. Groom, A.J. Avery, D. Boot and K. Thornhill, Age and proximity to death as predictors of GP care costs: Results from a study of nursing home patients, Health Economics 9 (2000) (8), pp. 733-738.

Perls (1997) T.T. Perls, Acute care costs of the oldest old, Hospital Practice 32 (1997) (7), pp. 123137.

Riley, Lubitz, Prihoda, \& Rabey (1987) G. Riley, J. Lubitz, R. Prihoda and E. Rabey, The use and costs of Medicare services by cause of death, Inquiry 24 (1987) (3), pp. 233-244.

Scitovsky (1994) A.A. Scitovsky, "The high cost of dying" revisited, Milbank Q 72 (1994) (4), pp. 561-591.

Serup-Hansen, Wickstrom, \& Kristiansen (2002) N. Serup-Hansen, J. Wickstrom and I.S. Kristiansen, Future health care costs-Do health care costs during the last year of life matter?, Health Policy 62 (2002) (2), pp. 161-172

Seshamani \& Gray (2003) M. Seshamani and A. Gray, Health care expenditures and ageing: An international comparison, Applied Health Economics and Health Policy 2 (2003) (1), pp. 9-16.

Seshamani \& Gray (2004) M. Seshamani and A. Gray, Ageing and health-care expenditure: The red herring argument revisited, Health Economics 13 (2004) (4), pp. 303-314.

Siegel \& Swanson (2004) J.J. Siegel and D. Swanson, The methods and materials of demography, Elsevier Academic Press, London (2004).

Statistics Netherlands (2005) Statistics Netherlands (2005). Lifetables for the Dutch population, 1999 and 2020. Voorburg: CBS-statline (www.cbs.nl).

Stearns \& Norton (2004) S.C. Stearns and E.C. Norton, Time to include time to death? The future of health care expenditure predictions, Health Economics 13 (2004) (4), pp. 315-327.

Steinmann, Telser, \& Zweifel (2005) L. Steinmann, H. Telser and P. Zweifel, The impact of aging on future healthcare expenditure (p. 23), University of Zurich, Zurih (2005).

Stooker et al. (2001) T. Stooker, J.W. van Acht, E.M. van Barneveld, R.C. van Vliet, B.A. van Hout and D.J. Hessing et al., Costs in the last year of life in The Netherlands, Inquiry 38 (2001) (1), pp. 73-80.

van der Heide et al. (2003) A. van der Heide, L. Deliens, K. Faisst, T. Nilstun, M. Norup and E. Paci et al., End-of-life decision-making in six European countries: Descriptive study, Lancet 362 (2003) (9381), pp. 345-350.

Yang, Norton, \& Stearns (2003) Z. Yang, E.C. Norton and S.C. Stearns, Longevity and health care expenditures: The real reasons older people spend more, Journal of Gerontology Series $B$ Psychological Sciences and Social Sciences 58 (2003) (1), pp. S2-S10.

Zweifel, Felder, \& Meiers (1999) P. Zweifel, S. Felder and M. Meiers, Ageing of population and health care expenditure: A red herring?, Health Economics 8 (1999) (6), pp. 485-496.

Zweifel, Felder, \& Werblow (2004) P. Zweifel, S. Felder and A. Werblow, Population ageing and health care expenditure: New Evidence on the "Red Herring", The Geneva Papers 29 (2004) (4), pp. 652666.

* Corresponding author. Tel.: +31302743273. 